\title{
Focus op talentvolle studenten geneeskunde: waar letten praktijkopleiders op?
}

\author{
F.J. Krings, J.Goedhuys
}

\section{Samenvatting}

Inleiding: Tijdens de stages en het afronden van de masteropleiding doen studenten geneeskunde praktijkervaring op en krijgen zij feedback van de praktijkopleider. Dit kan van invloed zijn op de latere specialisatiekeuze. Hoewel voor de praktijkbeoordeling van studenten criteria beschikbaar zijn, weten we weinig over wat voor de praktijkopleiders doorslaggevend is bij het vormen van een mening over de geschiktheid van de student voor het desbetreffende specialisme. Het doel van onze studie was te achterhalen in welke (kritische) beroepssituatie een praktijkopleider de getalenteerde van de niet-getalenteerde student denkt te kunnen onderscheiden.

Methode: Met gebruikmaking van de Critical Incident Technique (CIT) is in 2009 een onderzoek uitgevoerd binnen vier medische disciplines (Huisartsgeneeskunde, Heelkunde, Interne Geneeskunde, Psychiatrie) en één groep arts-onderzoekers, met een groepsgrootte van steeds vijf tot zes praktijkopleiders. Er zijn 26 semigestructureerde interviews naar critical incidents uitgevoerd, waarvan de resultaten intradisciplinair ter goedkeuring zijn voorgelegd. Handelingsresultaten uit de critical incidents waarover consensus werd bereikt zijn, op basis van het CanMEDS model, geanalyseerd op het soort competentiegebied.

Resultaten: In iedere onderzoeksgroep is consensus bereikt over een minimum set aan critical incidents (drie tot zes critical incidents). De critical incidents waarover consensus is verkregen, zijn gericht op het klinisch en wetenschappelijk handelen, communicatie, leiderschap en samenwerking. De resultaten suggereren dat praktijkopleiders uit verschillende disciplines zich onderscheiden door critical incidents waarin niet-medisch technische competenties van belang zijn.

Conclusie: Voor het ontdekken van talentvolle personen hebben praktijkopleiders slechts enkele critical incidents nodig. Praktijkopleiders uit de medische disciplines letten allen, naast klinisch handelen, ook op communicatief gedrag. Vooral voor praktijkopleiders uit de Huisartsgeneeskunde en de Psychiatrie blijkt communicatie een belangrijke indicator te zijn. De praktijkopleiders uit de overige disciplines onderscheiden zich vooral op de aandacht voor samenwerking en wetenschappelijke activiteiten. Arts-onderzoekers concentreren zich voornamelijk op wetenschappelijke activiteiten en de communicatie daarover. (Krings FJ, Goedhuys J. Focus op talentvolle studenten geneeskunde: waar letten praktijkopleiders op? Tijdschrift voor Medisch Onderwijs 2011;30(6):334-343.)

\section{Inleiding}

Het kiezen van een specialisatie is voor sommige studenten geneeskunde een lastige aangelegenheid. Soms lijkt hun keuze aan het begin van de bacheloropleiding al redelijk vast te staan, maar gaandeweg de opleiding rijzen er twijfels ${ }^{1}$ en blijken meerdere opties mogelijk en ook passend.

Een eerlijk carrièreadvies over de geschiktheid voor een bepaalde specialisatie 
is voor de student van wezenlijk belang. Immers, gezien de opleidingsduur, de opleidingskosten en de grote inspanningen van de student en de opleiders dient uitval ten gevolge van een verkeerde specialisatiekeuze voorkomen te worden. Frei et al. constateren dat carrièrebegeleiding (mentoring) een belangrijke functie heeft in de loopbaanontwikkeling van studenten geneeskunde. ${ }^{2}$ Studenten zullen niet alleen een bewustere keuze maken, ook de studieprestatie, de interesse in wetenschappelijk onderzoek en het welzijn van de student worden erdoor verhoogd. Een belangrijk aspect van carrièrebegeleiding is dat de mentor met de student carrièreopties bespreekt.

De kenmerken die het functioneren van een medisch specialist kunnen voorspellen zijn nog niet goed bekend. Uit onderzoek is wel gebleken dat de studieresultaten die behaald zijn tijdens de opleiding geneeskunde het latere functioneren in de praktijk slecht tot matig voorspellen.-6 Daar staat tegenover dat er wel aanwijzingen zijn voor de samenhang tussen onprofessioneel gedrag tijdens de opleiding geneeskunde en het opgelegd krijgen van disciplinaire maatregelen als praktiserend arts. $^{7-8}$ Van oudsher vertrouwen wij bij het beoordelen van de geschiktheid van studenten op het oordeelsvermogen van de praktijkopleiders (mentor). Zij hebben een goede kijk op wat echt van belang is om in de praktijk te kunnen functioneren en ze kunnen vaak teruggrijpen op jarenlange ervaring in het begeleiden van studenten. Hun inschatting over de geschiktheid en de daarop gebaseerde feedback kan voor de student van doorslaggevende betekenis zijn voor de carrièrekeuze.

Een onderzoekstechniek naar determinanten van al of niet succesvol functioneren is de Critical Incident Technique (CIT). ${ }^{9-11}$ Deze kwalitatieve onderzoekstechniek wordt onder andere gebruikt om de inhoud te bepalen van werkgerelateerde instrumenten voor selectie en beoordeling, zoals interviews, opdrachten voor assessment centers en gestandaardiseerde testen (bijvoorbeeld Situational Judgement Tests). Verder wordt de CIT ook gebruikt binnen het onderwijs. Voorbeelden hiervan zijn het ontwikkelen van functiebeschrijvingen en leerplannen. ${ }^{9-10}$ Ook voor het medisch onderwijs en onderzoek wordt de CIT aanbevolen ${ }^{12-14}$ en gebruikt voor functieanalyse ten behoeve van selectie- en beoordelinginstrumenten, voor zowel vakkundigheid als professionaliteit. ${ }^{15-21}$

Om antwoord te geven op de vraag op basis waarvan een praktijkopleider de getalenteerde student van de niet-getalenteerde denkt te onderscheiden, hebben wij een kwalitatief onderzoek uitgevoerd naar critical incidents (CI's), ook wel kritische beroepssituaties genoemd.

\section{Methode}

Het onderzoek naar CI's, waarin de talentvolle student geneeskunde zich duidelijk van de minder getalenteerde onderscheidt, werd uitgevoerd van juni 2009 tot en met januari 2010. Hiervoor is gebruik gemaakt van Flanagans CIT. Dit onderzoek vond plaats voor vier specialisaties (Huisartsgeneeskunde, Heelkunde, Interne Geneeskunde, Psychiatrie) en de discipline van arts-onderzoeker. Wij zochten naar deelnemers met een excellente staat van dienst als praktijkopleider (van vijfde- en/of zesdejaars studenten), en met de bereidheid deel te nemen aan een interview en consensusrondes. Om pragmatische reden is ervoor gekozen het totaal aantal respondenten per subgroep tot vijf à zes personen te beperken. De respondenten zijn geïdentificeerd via de sneeuwbalmethode, startend met de door medewerkers van de Dienst Onderwijs Geneeskunde van de Fa- 
culteit Geneeskunde van de Katholieke Universiteit Leuven (K.U.Leuven) aangewezen 'excellent functionerende' praktijkopleiders. Aan de benaderde personen is eveneens gevraagd binnen de eigen discipline een excellente praktijkopleider aan te wijzen. De aangewezen persoon werd vervolgens eveneens voor deelname aan het onderzoek benaderd. Bij het bereiken van vijf personen per specialisme, is gestopt met het benaderen van potentiële respondenten. Omdat het onduidelijk was of één van de respondenten uit de groep van Interne Geneeskunde voor het gehele proces beschikbaar kon zijn, is in deze groep een zesde respondent opgenomen. In totaal werden 31 personen benaderd, waarvan 26 instemden tot deelname. Alle respondenten zijn ervaren professionals en nauw betrokken bij de praktijkopleiding en het begeleiden van vijfdejaars studenten geneeskunde van de K.U. Leuven.

\section{Interviewronde}

Voor de interviews is conform de CIT een semigestructureerde vragenlijst opgesteld. Deze is in een proefinterview met één praktijkopleider uit de specialisatie Huisartsgeneeskunde, in aanwezigheid van een peer reviewer, getest. Vervolgens zijn de respondenten op de eigen werklocatie geïnterviewd (retrospective self-report).

Aan de respondenten werd gevraagd situaties te benoemen waarin zij talentvolle en minder talentvolle studenten hebben zien functioneren. Vervolgens werden die situaties nader uitgevraagd. Achtereenvolgens werd gevraagd naar contextuele aspecten, de kerntaak en het mogelijk dilemma in die situatie, het feitelijk gedrag (positief en negatief) van de student in kwestie, en het geboekte resultaat. Daarna werden de respondenten uitgevraagd over de interpretatie (kwalificatie) die zij aan het geobserveerde gaven (gepercipieerde mentaliteit, waarden en normen en identiteitsbeleving van de student).

De interviews vonden plaats tussen juni en oktober 2009, werden digitaal opgenomen, verbatim uitgeschreven, en handmatig geanalyseerd. De transcripties zijn ter 'member check' voorgelegd aan de respondenten. Nadat (meestal in tweede instantie) alle respondenten instemden met het eigen transcript, zijn deze per specialisme tot één document verwerkt. Deze documenten zijn per discipline aan de respondenten ter consensusvorming voorgelegd.

Tijdens het interview werd eerst ruimte gegeven om te definiëren wat men verstaat onder een gekwalificeerd en talentvol (student)specialist. Vervolgens kregen de respondenten de opdracht een feitelijk gebeurde situatie (CI) te beschrijven waarin ze een student als talentvol bestempelden. Eveneens is gevraag naar situaties waarin heel duidelijk werd dat men te maken had met niet-talentvolle studenten. Het interview werd zodanig gestuurd dat eerst de context en vervolgens pas het gedrag en de waardering daarvan beschreven werden.

\section{Consensusvorming}

In de tweede fase van het onderzoek lag de focus op consensusvorming. Bepaald werd welke CI's minimaal noodzakelijk zijn om een talentvol student aan te duiden. Door onverenigbare agenda's kon echter alleen voor de groep van huisartsen en van arts-onderzoekers een fysieke bijeenkomst georganiseerd worden. Voor de overige groepen zijn twee schriftelijke Delphi-rondes gehouden. De data van deze groepsactiviteiten zijn telkens vervat in één document en wederom ter 'member check' voorgelegd aan de groepsleden. Consensus over de minimum set aan CI's is voor alle groepen in de tweede aanbieding verkregen. 
$\mathrm{Na}$ consensusvorming zijn de CI's nader onderzocht met het CanMEDS model als referentiekader. Hiervoor werd per CI geanalyseerd of de tekst onder de kopjes 'resultaat' en 'interpretatie' kon worden toegeschreven aan een of meerdere competentiegebieden van het CanMEDS model. Voor deze analyse werden de respondenten niet verder benaderd.

\section{Resultaten}

Tijdens de interviews werden per groep tussen de zeven en zestien CI's gevonden, met een totaal van 63 CI's. Deze werden door de respondenten tijdens de consensusrondes, door samenvoeging van vergelijkbare CI's, gereduceerd tot drie à zes CI's (totaal 22 CI's). De CI's waarover consensus is bereikt zijn te vinden in Tabel 1 . De respondenten zijn van mening dat met deze specialismegebonden sets van CI's kan worden vastgesteld of iemand voldoende getalenteerd is voor het onderhavige specialisme. Uitgeschreven voorbeelden van de CI's zijn te vinden in de Boxen 1 en 2.

Alle CI-sets bevatten een CI waarin de student een presentatie/overdracht geeft aan collegae. Bij de groepen van de klinische specialisten gaat het daarbij om een patiëntencasus en bij de groep arts-onderzoekers over een onderzoeksidee en/of experiment. In de sets van de huisartsen, internisten en psychiaters zijn CI's te vinden die gaan over het consultatiegesprek. Bij deze CI's gaat het inhoudelijk vooral om het klinisch redeneren, zoals het komen tot een diagnose en het bepalen van de juiste therapie. CI's die zich richten op samenwerking met andere hulpverleners zijn te vinden in de sets van de groep Heelkunde en Psychiatrie. CI's gericht op wetenschappelijke activiteiten zijn te vinden in de sets van de groep Heelkunde en de groep arts-onderzoekers. Een overzicht van het soort activiteiten waar de CI's per groep aan refereren, is gegeven in Tabel 2. Van de 22 CI's waarover consensus bestaat, zijn 13 in belangrijke mate gerelateerd aan het klinisch handelen en 11 aan communicatieve activiteiten. Vier CI's zijn gerelateerd aan wetenschappelijk handelen en twee aan samenwerken. Ten slotte is er nog één CI waarin activiteiten van leiderschap tot uiting komen.

\section{Diversiteit in Critical Incidents}

De resultaten suggereren dat communicatief optreden voor alle disciplines van belang is, evenals het klinische handelen (klinisch redeneren) voor de vier groepen van klinisch specialisten. Voornamelijk de groep huisartsen en psychiaters formuleerden communicatiegerelateerde CI's. De groep arts-onderzoekers beschreef CI's die vooral gericht zijn op het wetenschappelijke handelen (onderzoeksmethodologie en techniek), waarbij ook communicatie een belangrijke rol speelt. Klinische handelingen komen in de CI's van de artsonderzoekers niet echt tot uitdrukking. Het wetenschappelijke handelen blijkt ook in sommige CI's van de specialismen Interne Geneeskunde en Heelkunde van belang te zijn. Tot slot komt samenwerking in de CI's van de groep Heelkunde en Psychiatrie als indicator voor talentvolle studenten naar voren. De groep van de Heelkunde kwam tot het breedste palet aan CI's (vijf soorten activiteiten).

\section{Beschouwing}

Wij onderzochten op basis waarvan praktijkopleiders een inschatting maken over de geschiktheid van een student voor een bepaald specialisme. Het technisch goed kunnen uitvoeren van een medische handeling is in onze tijd onvoldoende om een goede specialist te zijn. Het is ook nodig dat men over excellente niet-technische vaardighe- 
Tabel 1. Critical Incidents waarover consensus is bereikt (getalenteerde en niet-getalenteerde personen kan men in deze situaties onderscheiden).

Huisarts (4 uit $7 \mathrm{Cl}$ 's)

- Consultatie van een kleine kwaal ${ }^{182}$

- Moeilijk gesprek met de patiënt (psychologisch) ${ }^{182}$

- Presenteren van een patiënt aan collegae ${ }^{2}$

- Motiverende gespreksvoering ${ }^{2}$

Heelkunde (5 uit $15 \mathrm{Cl}$ 's)

- Heelkundig handelen (motorisch) ${ }^{1}$

- Prioriteren van activiteiten (spoedindicatie) ${ }^{185}$

- Rapportage van de toestand van de patiënt (klinisch redeneren) ${ }^{182}$

- Wetenschappelijke opdracht ${ }^{4}$

- Samenwerking op het operatiekwartier of de verpleegafdeling ${ }^{3}$

Interne Geneeskunde (4 uit 16 Cl's)

- Zaalronde met collegae ${ }^{4}$

- Consultatie op de verpleegafdeling ${ }^{1}$

- Consultatie op de urgentieafdeling ${ }^{1}$

- Een patiënt presenteren aan collegae ${ }^{182}$

Psychiatrie (6 uit 12 Cl's)

- Consultatie (diagnose-gericht) voor een klein psychiatrisch probleem ${ }^{182}$

- Consultatie (therapie-gericht) voor een klein psychiatrisch probleem ${ }^{182}$

- Consultatie voor een moeilijke patient ${ }^{182}$

- Dialoog met de mentor of collegae 182

- Samenwerken met andere hulpverleners ${ }^{3}$

- Interventie toepassen ${ }^{1}$

Arts-onderzoeker (3 uit $13 \mathrm{Cl}$ 's)

- Dialoog over onderzoek ${ }^{284}$

- Oplossen van een technisch probleem ${ }^{4}$

- Presenteren van een idee/experiment aan collegae ${ }^{2}$

${ }^{1}$ klinisch handelen; ${ }^{2}$ communiceren; ${ }^{3}$ samenwerken; ${ }^{4}$ wetenschappelijk handelen; ${ }^{5}$ eiderschap; ${ }^{6}$ professionaliteit

Tabel 2. Aantal Cl's per specialisme gerelateerd aan het soort activiteit.*

\begin{tabular}{lccccc}
\hline & $\begin{array}{c}\text { Klinisch } \\
\text { handelen }\end{array}$ & $\begin{array}{c}\text { Commu- } \\
\text { niceren }\end{array}$ & $\begin{array}{c}\text { Samen- } \\
\text { werken }\end{array}$ & $\begin{array}{c}\text { Wetenschappelijk } \\
\text { handelen }\end{array}$ & $\begin{array}{c}\text { Leider- } \\
\text { schap }\end{array}$ \\
\hline Huisartsgeneeskunde & 2 & 4 & 0 & 0 & 0 \\
Heelkunde & 3 & 1 & 1 & 1 & 1 \\
Interne Geneeskunde & 3 & 1 & 0 & 1 & 0 \\
Psychiatrie & 5 & 4 & 1 & 0 & 0 \\
Arts-onderzoeker & 0 & 2 & 0 & 2 & 0 \\
& 13 & 12 & 2 & 4 & 1 \\
\hline
\end{tabular}

* één Cl kan refereren aan meerdere activiteiten (zie ook Tabel 1). 
den beschikt. Dit is de reden dat in België en Nederland het CanMEDS model is omarmd. De samenstellingen van de disciplinegebonden CI-sets geven dat eveneens weer. Hoewel alle groepen in hun 'minimum set' CI's hebben opgenomen die gerelateerd zijn aan het technisch (klinisch) handelen, blijken zij ook aan communicatie, samenwerking en leiderschap te refereren.

De groep Heelkunde toont ten opzichte van de overige groepen een relatief breed palet aan CI's. Een beeld dat in lijn is met de bevindingen van Yule et al. ${ }^{22}$ die in hun review over de niet-technische vaardigheden van chirurgen, de hoofdcategorieën communicatie, teamwork, leiderschap en besluitvorming identificeerden.

De CI's van de groep huisartsen focussen vooral op de klinische expertise en communicatie. Uit de uitwerking van de CI's blijkt ook dat het aangaan van een behandelrelatie met de patiënt zeer belangrijk wordt gevonden. In een CI-focusgroepstudie naar noodzakelijke competenties voor huisartsen vonden Patterson et al. ${ }^{21}$, naast klinische expertise en communicatie, negen additionele categorieën van gedragsbeschrijvingen, die overigens ook wel weer te herleiden zijn naar de CanMEDS competentiegebieden. Dit zijn: 'empathy and sensitivity' (communicatie), 'conceptual thinking and problem solving' (wetenschappelijk handelen), 'personal attributes' (kernkwaliteiten), 'personal organisation and administration skills' (organiseren), 'personal integrity' (professioneel handelen), 'coping with pressure' (professioneel handelen), 'managing others and team involvement' (samenwerking), 'legal, ethical and political awareness' (maatschappelijk/professioneel handelen) en 'learning and personal development' (wetenschappelijk/professioneel handelen). Vergelijkbare studies die als referentiepunt kunnen dienen zijn voor de overige groepen niet gevonden.
Doordat in dit onderzoek slechts een beperkt aantal respondenten is benaderd, en de intentie was alleen de meest essentiële CI's te exploreren, is er ook slechts een beperkt aantal (63) CI's geformuleerd. Dit verklaart mogelijk het verschil in het aantal CI's voor de huisartsengroep in ons onderzoek (vier CI's) en dat van Patterson et al. ${ }^{21}$ (11 CI's). De betekenis hiervan kan zijn dat wij mogelijk voor deze groep het verzadigingspunt nog niet bereikt hadden. Anderzijds lag het in onze bedoeling alleen de meest essentiële CI's te exploreren, terwijl Patterson et al. zochten naar een zo uitvoerig mogelijke verzameling van CI's. Om te komen tot een objectieve beoordeling van studenten wil men immers een groot aantal CI's benutten, terwijl voor een ervaren praktijkopleider een zeer beperkt aantal CI's voldoende kan zijn om te weten wat voor vlees hij in de kuip heeft. Het feit dat de 63 CI's teruggebracht konden worden naar 22, suggereert naar onze mening dat er sprake kan zijn van dataverzadiging. In de 60-90 minuten durende interviews hadden de respondenten veelal na $50 \mathrm{mi}$ nuten geen nieuwe inbreng meer.

Bij gebrek aan middelen is het onderzoek uitgevoerd door slechts één onderzoeker die terzijde werd gestaan door een 'critical friend'. Hierdoor konden wij aan enkele kwaliteitscriteria voor de 'credibility' en 'trustworthiness' van de $\mathrm{CIT}^{10}$ onvoldoende tegemoet komen. Het onderzoek had aan kwaliteit kunnen winnen als wij een onafhankelijke expert hadden kunnen inzetten die delen van de analyse zelfstandig had kunnen uitvoeren of controleren ('interview fidelity', 'independent extraction of critical incidents'). Verder was het door het geringe aantal respondent per subgroep niet zinvol om de "participation rate' (aantal respondenten dat een specifieke CI beschrijft gedeeld door het totaal aantal respondenten) te bereke- 
nen. Daar staat tegenover dat de 'descriptive validity' is gewaarborgd door van de interviews en de groepsdiscussies digitale opnames te maken, waardoor het mogelijk was tijdens de analyse steeds weer terug te luisteren wat de respondenten precies zeiden. Alle CI's die door de respondent als CI's werden aangemerkt zijn opgenomen in de analyse. De analyses zijn voorgelegd aan de respondenten voor 'participant cross-check', zodat deze steeds gevalideerd werden. Door het inzetten van een 'critical friend' die iedere stap in het onderzoek actief volgde, inclusief het categorisatieproces van de CI's, is tegemoet gekomen aan het criterium 'independent judges'. De resultaten zijn naar onze mening valide en betrouwbaar, maar mogelijk niet uitputtend.

\section{Conclusie}

Het gebruik van de CIT blijkt een goede methode om te ontdekken welke situaties voor praktijkopleiders richtinggevend zijn bij het inschatten van de beroepsmatige potenties van studenten geneeskunde. $\mathrm{Zij}$ hebben hiervoor blijkbaar slechts enkele CI's nodig. De praktijkopleiders uit de medische disciplines focussen daarbij op si- tuaties waarin, naast klinische, communicatieve competenties van belang zijn. Vooral voor praktijkopleiders uit de Huisartsgeneeskunde en de Psychiatrie blijkt communicatie een belangrijke indicator te zijn voor het vermogen van een student. De praktijkopleiders uit de overige disciplines onderscheiden zich vooral op de aandacht voor samenwerking en wetenschappelijke activiteiten. De arts-onderzoekers onderscheiden zich van de deelnemers uit de overige disciplines door het feit dat zij zich niet richten op de klinische, maar op de wetenschappelijke activiteiten. Grootschalig onderzoek naar de CI's binnen alle medische disciplines is gewenst, omdat daardoor zichtbaar wordt wat in de ogen van de praktijkopleiders de essentiële voorspellers zijn van talentvolle studenten.

\section{Dankwoord}

De auteurs danken Prof. dr. B. Himpens, decaan van de faculteit Geneeskunde van de K.U. Leuven voor zijn steun aan dit onderzoek. Verder danken wij alle respondenten die, ondanks hun spaarzame vrije tijd, ruimte wisten te maken om deel te nemen aan ons onderzoek.

Box 1. Voorbeeld van Critical Incident.

\section{Psychiatrie - Consultatie (diagnose-gericht) voor een klein psychiatrisch probleem}

Dilemma: Stellen van intieme vragen op het juiste tijdstip.

Taak: In deze situatie voert de student/arts een consultatiegesprek met een patiënt. De mentor is daarbij aanwezig. De essentie van dit gesprek is om te begrijpen wat er met de patiënt aan de hand is en tot een diagnose te komen. Daarbij zal de student/arts zeer persoonlijke vragen moeten stellen die zodanig getimed zijn, dat de patiënt bereid is om daar antwoord op te geven. Het is aan de student/ arts om een sfeer van openheid, vertrouwen en rust te creëren waarin dat ook mogelijk is. Hiervoor is het noodzakelijk dat de student/arts aanvoelt wanneer gestuurd kan worden en wanneer niet. De student/arts zal zich daarbij steeds moeten afvragen of en zo ja wanneer, bepaalde vragen gesteld gaan worden en momenten van stilte gebruiken als ondersteunend middel voor de gespreksvoering. 
Box 1. Vervolg

Professioneel gedrag: Om het consultatiegesprek goed te laten verlopen laat de student/arts vooral de patiënt zelf aan het woord. Hij denkt na over welke mogelijkheden er zijn en stelt aan de hand daarvan bepaalde vragen. Hij start in eerste instantie met open vragen om met de antwoorden die de patiënt geeft verschillende ziektebeelden in te kaderen. Alle mogelijke veronderstellingen worden geëxploreerd, zonder dit te gehaast te doen. In 2e termijn worden de ontdekte kaders met meer gerichte en soms gesloten vragen getoetst. De student/arts gebruikt daarbij het middel van gesprekstiltes en zet de volgende vraag pas in als de patiënt daar gereed voor is. Tijdens het gesprek gaat de student/arts soms met de patiënt mee en soms geeft hij sturing. De student/arts gebruikt empathie (te zien aan non-verbaal gedragingen van nabijheid) als middel om te begrijpen en houdt professionele afstand tot de patiënt (eigen emoties de baas zijn). De student/arts blijft ook bij agressief gedrag en pogingen tot "Einschüchterung" professioneel en pareert dit adequaat. Bij het overwegen van een passende therapie wordt zowel farmacotherapie als gesprekstherapie overwogen of een combinatie van beiden.

Resultaten: De consultatie verloopt vlot, waarbij de patiënt de ruimte heeft om in eigen tempo vragen te beantwoorden en invloed te behouden op het gesprek. De patiënt behoudt daarbij "interne rust" (waar te nemen aan non-verbaal gedrag) en het vertrouwen (laat zich ook sturen) in de student/arts als behandelaar. Het gesprek blijft de focus houden op de psychiatrische problemen van de patiënt en de antwoorden van de patiënt zijn uitgebreid en diepgaand. Stiltes zijn functioneel en ondersteunen het denkproces van de patiënt (waar te nemen aan non-verbaal gedrag van de patiënt dat passend is bij denkprocessen en waar te nemen aan antwoorden die aansluiten op de gestelde vragen). Uiteindelijk komt de student/arts tot een werkbare synthese. De patiënt uit zich lovend over de student/arts in richting van de mentor.

Interpretatie van de observator: Uw indruk als mentor kan zijn dat $\mathrm{u}$ de student/arts ziet als iemand die intrinsiek geïnteresseerd is in de psychiatrie en er van uit gaat dat psychiatrische problemen ernstig zijn en iedereen kunnen overkomen. lemand met oprechte betrokkenheid (empathie) bij de patiënt en die daadwerkelijk iets wil betekenen voor die patiënt, zonder daarbij voyeuristisch te worden of zich laat meeslepen door de misère van de patiënt.

Ook kunt $\mathrm{u}$ de indruk hebben dat de student/arts de gesprekstechnieken van het psychiatrisch gesprek in de vingers heeft en zelfverzekerd overkomt. Dat hij gevoelsmatig het tijdstip weet te bepalen voor de volgende vraag. De student geeft de indruk dat hij graag naar de patiënt luistert. Woorden als takt, vriendelijkheid en rust kunnen daarbij in $u$ opkomen. Verder kunt $u$ de indruk hebben dat de student/arts ook beslissingen weet te nemen en bij het bepalen van de behandeling niet alleen farmacotherapeutisch denkt, gelooft in de veranderbaarheid van bepaalde psychiatrische problemen, maar ook weet waar de grenzen daarvan kunnen liggen. Met andere woorden dat de student/arts de indruk geeft te denken: "Wat ik hier doe heeft kans op succes, er zijn mogelijkheden tot interventie, ondanks de beperkingen die er zijn". 
Box 2. Voorbeeld van Critical Incident

\section{Huisartsgeneeskunde - Klinisch consultatie kleine kwaal}

Dilemma: Op afstand blijven of betrokken raken.

Taak: In deze situatie voert de student/arts een consultatiegesprek met een patiënt. De mentor kan daarbij op de achtergrond aanwezig zijn of is in de buurt voor als er vragen zijn. Het consult betreft een zogenoemde "kleine kwaal". De student/arts heeft de taak om de anamnese af te nemen, eventueel lichamelijk onderzoek te verrichten en tot een werkdiagnose te komen. De student/ arts heeft eveneens de taak om een behandelvoorstel aan de patiënt voor te legen en dit met de patiënt te bespreken. Van de student/arts wordt voorts verwacht dat hij bevindingen en keuzes kan beargumenteren en bespreken met een andere professional (in dit geval de mentor).

De student/arts zal moeten kiezen uit een aantal min of meer voor de hand liggende diagnoses, waarbij de context gebonden waarschijnlijkheid een belangrijke rol speelt. Voor het lichamelijk en aanvullend onderzoek zal de student/arts de wenselijkheid én de diagnostische waarde dienen te bepalen. Wat de behandeling betreft is de keuze bepaald door "niets doen" en de tijd te laten werken óf een feitelijke behandeling te kiezen. De verschillende opties zijn aan de patiënt voor te leggen op een wijze dat deze een weloverwogen keuze kan maken.

Professioneel gedrag: Om effectief te kunnen handelen, neemt de student/arts een houding aan waardoor de autonomie van de patiënt in takt blijft. De patiënt wordt betrokken bij het kiezen van de behandeling, waarbij aandacht is voor diens historie, huidige situatie en eventueel relevante toekomstperspectieven. Bestaande onvermijdelijke onzekerheden worden in de overwegingen meegenomen, evenals andere potentiële diagnoses.

De student/arts weet hoofd- en bijzaken duidelijk te scheiden en werkt sterk patiëntgericht i.p.v. pathologie gericht. Belangrijke aspecten van het onderzoek worden gedocumenteerd. De student/ arts stelt de juiste vragen op het juiste moment en is daarbij hoffelijk, luistert en biedt steun aan de patiënt. De student/arts zoekt aansluiting bij de belevingswereld van de patiënt en legt eigen waarden, normen en emoties niet aan de patiënt op.

Resultaten: De consultatie verloopt vlot en soepel en er wordt trefzeker bepaald of er sprake is van een ernstig gezondheidsprobleem. De student/arts komt tot de juiste diagnose en een passend behandelvoorstel. Het e-dossier is zodanig informatief dat een ander huisarts in voorkomend geval de patiënt probleemloos kan overnemen. In de communicatie met de patiënt weet de student/arts snel "rapport" op te bouwen en de balans te vinden tussen menselijke nabijheid en professionele afstand (duidelijke verdeling van rol en verantwoordelijkheden). De patiënt voelt zich op zijn gemak.

Interpretatie van de observator: Uw indruk als mentor kan zijn dat de patiënt de student/arts ziet als een bekwame arts. $U$ kunt verder de indruk hebben dat de student/arts zelfstandig en zelfverzekerd te werk gaat en daarbij de eigen professionele grenzen en verantwoordelijkheden in acht neemt. Ook kunt $u$ de indruk hebben dat de student/arts oprecht geïnteresseerd en geëngageerd is en zichtbaar plezier heeft aan het werk van huisarts en daarvoor ook de nodige maturiteit heeft. De student geeft de indruk verbaal sterk te zijn en de eigen emoties onder controle te hebben. 


\section{Literatuur}

1. Compton MT, Frank E, Elon L, Carrera J. Changes in U.S. Medical Students' Specialty Interests over the Course of Medical School. J Gen Intern Med 2008;23(7):1095.

2. Frei M, Stamm M, Buddeberg-Fischer B. Mentoring programs for medical students - a review of PubMed literature 2000-2008. BMC Med Educ 2010;10(32):14.

3. Woloschuk W, McLaughlin K, Wright B. Is undergraduate performance predictive of postgraduate performance? Teach Learn Med 2010;22 (3):202-4.

4. Hamdy H, Prasad K, Anderson MD, Scherpbier A, Wiliams R, Swierstra R, et al. BEME systematic review: predictive values of measurements obtained in medical schools and future performance in medical practice. Med Teach 2006; 28(2):103-16.

5. Reede JY. Predictors of succes in medicine. Clin Orthop Relat Res 1999;362:72-7.

6. Kuncel NR, Sackett SA. Fact and Fiction in Cognitive Ability Testing for Admissions and Hiring Decisions. Current Directions in Psychological Science 2010;19:339-45.

7. Papadakis MA, Teherani A, Banach MA, Knettler TR, Rattner SL, Stern DT et al. Disciplinary Action by Medical Boards and Prior Behavior in Medical School. New Eng J Med 2005;353:2673-82.

8. Teherani A, Hodgson CS, Banach MA, Papadakis MA. Domains of Unprofessional Behavior During Medical School Associated with Future Disciplinary Action by a State Medical Board. Acad Med 2005;80(10sup):s17-s20.

9. Koch A, Strobel A, Kici G, Westhoff K. Quality of the Critical Incident Technique in practice: Interrater reliability and users' acceptance under real conditions. Psychology Science Quaterly 2009; 51:3-15.

10. Butterfield JD, Borgen WA, Amundson NE, Maglio AT. Fifty years of the critical incident technique: 1954-2004 and beyond. Qualitative Research 2005; 5:475-97.

11. Flanagan JC. The critical incident technique. Psychological Bulletin 1954;51:327-60.

12. Bradley C. Turning anecdotes into data: the critical incident technique. Family Practice 1992;9(1):98-103.

13. Newble DI. The critical incident technique: a new approach to the assessment of clinical performance. Med Educ 1983;17(6):401-3.

14. Dunn M, Hamilton D. The critical incident technique: a brief guide. Med Teach 1986;8(3):207-15.
15. Sim MG, Kamien M, Diamond MR. From novice to proficient general practitioner: a critical incident study. Austr Fam Physician 1996;25(9 (suppl 2)): s59-s64.

16. Diamond MR, Kamien M, Sim MG, Davis J. A critical incident study of general practice trainees in their basic general practice. Medical Journal of Australian 1995;162(6):321-4.

17. Altmaier EM, From RP, Pearson KS, Gorbatenkoroth KG, Ugolini KA. A prospective study to select and evaluate anesthesiology residents: pase I, the critical incident technique. J Clin Anest 1997; 9(8):629-36

18. Blouin D, Dagnone JD. Performance criteria for emergency medicine residents: a job analysis. Can J Emerg Med 2008;10(6):539-44.

19. Hodges D, McLachlan JC, Finn GM. Exploring reflective 'critical incident' documentation of professionalisme lapses in a medical undergraduate setting. BMC Med Educ 2009;9(44).

20. Patterson F, Ferguson E, Thomas S. Using job analysis to identify core and specific competencies: implications for selection and recruitment. Med Educ 2008;42:1195-204

21. Patterson F, Ferguson E, Lane P, Farrell K, Martlew J, Wells A. A competency model for general practice: implications for selection, training, and development. Br J Gen Pract 2000;50(188-193).

22. Yule S, Flin R, Paterson-Brown S, Maran N. Nontechnical skills for surgeons in the operating room: A review of the literature. Surgery 2006; 139:140-9.

De auteurs:

Frank J. Krings is docent aan de Fontys Hogeschool Verpleegkunde, Eindhoven.

Dr. J. Goedhuys is hoofddocent aan de Faculteit Geneeskunde, Katholieke Universiteit Leuven / Academisch Centrum voor Huisartsgeneeskunde, Leuven, België.

Correspondentieadres:

Frank J. Krings, Fontys Hogeschool Verpleegkunde, postbus 347, 5600 AH Eindhoven. Tel.: 06-12481474. E-mail:f.krings@fontys.nl

Belangenconflict: geen gemeld

Financiële ondersteuning: geen gemeld 


\section{Summary}

Background: During clinical clerkships, medical students have experiences in clinical practice where they receive feedback from supervisors. This can affect their choice of specialty for postgraduate training. Despite the existence of selection criteria, little is known about which factors affect the opinions of supervisors regarding the suitability of students for a specialty. The aim of our study was to identify (critical) incidents that helped supervisors to distinguish between talented and non-talented students.

Methods: In 2009, we conducted a study using the Critical Incident Technique in four medical disciplines (general practice, surgery, general medicine, psychiatry) and among a group of physician-researchers. Each group consisted of 5-6 supervisors. We conducted 26 semi-structured interviews focusing on critical incidents, followed by intra-disciplinary consensus rounds. The behaviours identified in this way were labelled using the competencies of the CanMEDS model.

Results: Each group reached consensus on a minimum set of critical incidents (3-6 critical incidents), focusing on the roles of medical expert, scholar, communicator, manager and collaborator. The focus of supervisors on important nonmedical competencies within the critical incidents differed depending on their discipline.

Conclusion: Supervisors needed only a few critical incidents to identify talented students. All the supervisors from the health care disciplines focused on the role of communicator in addition to the role of medical expert. Supervisors in general practice and psychiatry, in particular, considered the role of communicator an important indicator of talent. The supervisors from other disciplines focused also on collaboration and scholarship. Physician-researchers focused mainly on the roles of scholar and communicator. (Krings FJ, Goedhuys J. Focus on talented medical students: which factors determine supervisors' opinions? Netherlands Journal of Medical Education 2011;30(6):334-344.) 